\title{
Conclusões dos Small Working Groups Integrados no V Simpósio Acta Médica Portuguesa
}

\section{Conclusions from the Small Working Groups Included in the $5^{\text {th }}$ Symposium Acta Médica Portuguesa}

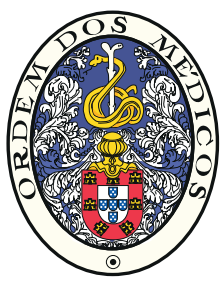

\author{
Acta Med Port 2016 Nov;29(11):681-682 - http://dx.doi.org/10.20344/amp.8478
}

A vertente prática do Simpósio anual promovido pela Acta Médica Portuguesa traduziu-se este ano na criação de quatro grupos de trabalho que, sob a orientação de personalidades de relevo nacional, transmitiram de forma dinâmica e interativa uma série de conteúdos relativos à escrita e publicação médica e científica.

Grupo A: Critérios de autoria: papel do estudante dentro da equipa de investigação

\section{Coach: Ivo Álvares Furtado}

Autor é quem pode assumir publicamente o conteúdo do trabalho. ${ }^{1} \mathrm{O} 1^{\circ}$ autor deve ser quem idealizou o trabalho, definiu os objectivos e a metodologia, recolheu os dados, analisou os resultados e redigiu o artigo. $^{2} \mathrm{O}$ último autor deve ser o orientador do grupo. Podem existir vários primeiros autores quando a sua contribuição é semelhante. Os agradecimentos são devidos a quem colaborou na realização do trabalho e não reúna critério de inclusão na lista de autores. ${ }^{2}$ Os estudantes devem ser integrados nos Grupos de Investigação ${ }^{3}$; devem participar ativamente em projectos de iniciação à investigação; podem também colaborar em projectos de investigadores séniores. Os projectos realizados por estudantes podem ocorrer durante a licenciatura com microprojectos numa perspectiva de liderança de grupos e de empreendedorismo - estudante gestor de projecto -, num âmbito multidisciplinar. ${ }^{4}$ Os microprojectos contribuem para a emergência de uma massa crítica alargada e participativa. ${ }^{5} \mathrm{~A}$ investigação deverá ser usada para a avaliação dos estudantes, e pode levar a dissertações de mestrado e teses de doutoramento. ${ }^{5}$

\section{REFERÊNCIAS}

1. Authorship and Authorship Responsibilities. [consultado 2016 ago 09]. Disponivel em: http://www.councilscienceeditors.org/resource-library/ editorial-policies/white-paper-on-publication-ethics/2-2-authorship-andauthorship-responsibilities/.

2. Montenegro MR, Alves VA. Critérios de autoria e co-autoria em trabalhos científicos. [consultado 2016 ago 09]. Disponível em: http:// dx.doi.org/10.1590/S0036-46651987000400001.

3. Universidade Portucalense. [consultado 2016 ago 09]. Disponível em: http://www.upt.pt/page.php?p=95, acesso em 2016/08/09.

4. U. Porto > Estudantes > Iniciativas: IJUP - Projetos LIDERA. [consultado 2016 ago 09]. Disponível em: https://sigarra.up.pt/up/pt/ web_base.gera_pagina?p_pagina=inicia $\%$ C $3 \% \mathrm{~A} 7 \% \mathrm{C} 3 \% \mathrm{~A} 30 \% 20$ $\%$ C3\%A0\%20investiga\%C3\%A7\%C3\%A30\%20na\%20u.porto $\% 20$ -\%20iniciativas:\%20ijup\%20-\%20projetos\%20lidera.

5. Outeirinho MF. Grupo Inter/Transculturalidades do ILCM. [consultado 2016 ago 09]. Disponível em: http://ilcml.com/blog/da-integracao-dainvestigacao-na-avaliacao-de-estudantes-como-estrategia-inclusiva/.

\section{Grupo B: Redes sociais e publicação científica}

\section{Coach: José Carona Carvalho}

A utilização das redes sociais como uma componente da promoção da publicação científica é cada vez mais disseminada pois assenta nos pressupostos de redes colaborativas. Este mecanismo representa no contexto digital a forma como hoje em dia, graças às tecnologias da informação e comunicação, se desenvolve a ciência, em rede, de forma colaborativa e sem barreiras geográficas, ou seja, num contexto global. Existem redes sociais mais genéricas como o Facebook e o Twitter e outras, mais específicas para o investigador, como o ResearchGate, Academia ou Mendeley. Estas últimas caracterizam-se por permitir a gestão e partilha das publicações, a obtenção de métricas próprias e a criação de redes de coautorias. Todos eles são sistemas alimentados de forma colaborativa e organizados em redes ou grupos. No caso do Mendeley possui ainda uma ferramenta para gestão de referências bibliográficas. Estas novas tendências levaram também a novas formas de identificação dos autores, e neste caso o serviço ORCID é o que pretende agregar as várias identidades e disponibilizar uma única forma conhecida internacionalmente para a identificação inequívoca do autor no vasto mundo da web. Esta tendência das redes sociais levou ainda à criação de métricas alternativas para avaliar o impacto efetivo dos trabalhos científicos. Além de medir o uso dos trabalhos através das consultas e downloads dos registos, é também considerada a opinião dos pares, através por exemplo de revisões públicas, assim como as citações dos trabalhos. Adicionalmente, as designadas "altmetrics" focam-se na obtenção de indicadores sobre partilhas nas redes, blogs, sistemas de bookmarks, etc. 


\section{Grupo C: Como escolher um título e elaborar bons resumos}

\section{Coach: João Massano}

O título e o resumo são trailers para a longa-metragem que é o artigo completo. Durante o processo de revisão enquadram o artigo para os editores e revisores e, após a sua publicação, são a forma de apresentação do artigo para o público-alvo. São fundamentais para que o artigo seja encontrado, lido, comentado e citado. Por isso, o autor deve empregar o tempo e esforço necessários na sua elaboração. Ambos devem cumprir as regras e adequarem-se ao estilo da revista escolhida. O título deve ser informativo, curto e conciso, indicando o tema principal do artigo e, se possível, o desenho do estudo. Os autores devem usar, no título, termos que sejam indexáveis como palavras-chave, o que facilitará buscas eficazes não só nas bases de dados tradicionais, mas também nos modernos motores de busca na world wide web. Por outro lado devem ser evitadas abreviaturas, à exceção das consagradas. O resumo deve ser estruturado de forma implícita ou explícita em várias secções: introdução, métodos, resultados e conclusões. A introdução deve ser curta e direta, enquadrando o problema e o objetivo do estudo. Nos métodos deve descrever-se a população, quais e como foram avaliadas as variáveis, e o desenho do estudo. A secção de resultados será a mais longa, listando os achados por ordem decrescente de importância, com tanto detalhe quanto possível. As conclusões devem indicar a mensagem chave decorrente do estudo, uma eventual mensagem secundária, e fornecer uma perspetiva futura em relação ao tema.

\section{Grupo D: Como manter o conhecimento up-to-date}

\section{Coach: António Vaz Carneiro}

O Special Working Group sobre o tema "Como manter o conhecimento up-to-date" reuniu alguns jovens médicos que discutiram os diversos tipos de informação clínica de suporte à decisão médica. Identificaram-se quatro áreas em que é necessária informação médica de alta qualidade: 1) a assistência aos doentes/pacientes, 2) a atualização dos conhecimentos médicos, 3) a docência pré e pós-graduada e, finalmente, 4) a investigação clínica. Cada uma destas áreas pode encontrar informação nos estudos originais que estão disponíveis em grandes bases de dados bibliográficos, mas a sua organização e síntese é substantivamente diferente em cada uma delas quando se deseja operacionalizar este conhecimento para a prática. Foi consenso geral que existe um significativo problema na atualização do conhecimentos em medicina e que é muito difícil conseguir acompanhar o fluxo de informação científica que é diariamente publicada. A fidedignidade das fontes de informação é habitualmente relacionada com o prestígio da revista onde se encontra publicada, uma abordagem criticada pela sua baixa validade. Existem metodologias de avaliação crítica da literatura biomédica que, utilizando grelhas de "guias" (questões) específicas, permitem a classificação dos artigos em termos da sua qualidade e usabilidade. Em termos da atualização dos conhecimentos, defendeu-se que dois sistemas de atualização (grátis ou não) são particularmente úteis: o BMJ Updates e o ACP Journal Club.

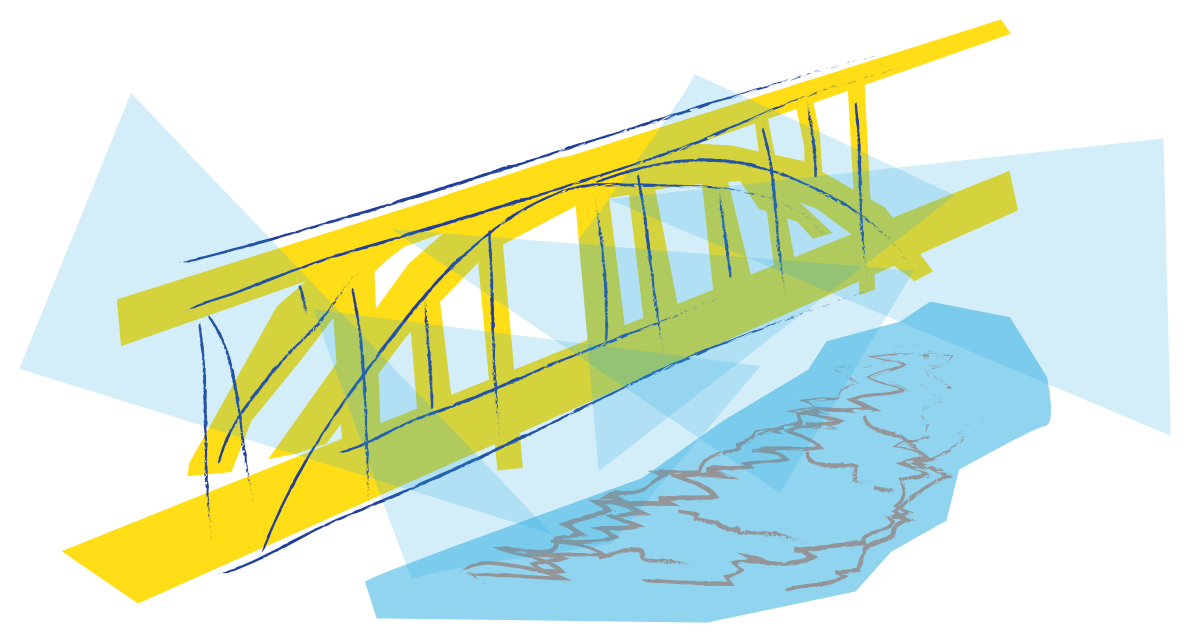

